\title{
PIK3CA NM_006218.1:C.1634A>T
}

National Cancer Institute

\section{Source}

National Cancer Institute. PIK3CA NM 006218.1:C.1634A>T. NCI Thesaurus. Code C98473.

A nucleotide substitution at position 1634 of the coding sequence of the PIK3CA gene where adenine has been mutated to thymine. 